\title{
Políticas de informação em tempos de governo eletrônico: um estudo preliminar sobre a governança informacional no estado de Minas Gerais
}

\author{
Information policy in times of electronic government: a preliminary study on Informational \\ Governance in the State of Minas Gerais
}

\begin{abstract}
Fernando Guerra
Mestrando em Administração Profissional pela FEAD. Especialista em Gestão Estratégica da Informação pela Universidade Federal de Minas Gerais - UFMG.

E-mail: fcgdguerra@gmail.com
\end{abstract}

\begin{abstract}
Rogério Luís Massensini
Mestre em Ciência da Informação e Especialista em Gestão Estratégica da Informação pela Universidade Federal de Minas Gerais - UFMG. Servidor Público do Estado de Minas Gerais. E-mail: rogeriomassensini@gmail.com
\end{abstract}

\begin{abstract}
Resumo
Este trabalho é um estudo preliminar com foco em políticas públicas específicas, que possui como objeto a informação eletrônica disponibilizada ao cidadão, por meio de políticas de informação governamental, no Estado de Minas Gerais. Segundo Ferguson (2002, p.129), há uma estratégia, utilizada pelo governo britânico, norteada por quatro princípios: "a criação dos serviços com base nas opções dos cidadãos; tornar o governo e seus serviços mais acessíveis; inclusão social; melhoria na utilização da informação”. Deste modo, esses princípios nos servem aqui como norteadores deste estudo, que objetiva preliminarmente listar os serviços eletrônicos mais acessados do governo de Minas Gerais, como resposta ao primeiro princípio. Para tanto, o estudo pretende utilizar-se dos dados apresentados pela Superintendência Central de Governança Eletrônica. O Portal MG disponibiliza vários serviços de interesse a sociedade, mas que são desconhecidos pelos cidadãos. Estes serviços necessitam de um trabalho de divulgação entre os cidadãos para que eles possam utilizar-se dos e-gov disponíveis nos sites governamentais para minimizar ou solucionar as demandas da sociedade e tentar reverter a fama de ineficiência da organização pública. Em sua dissertação e trabalho apresentado no Enancib XI, Massensini (2010) aponta a necessidade de se investir em telecentros, como pontos de acesso público; em letramento informacional, como ensino da linguagem digital que capacita o cidadão para o uso das TICs (Tecnologia da Informação e Comunicação) e participação do governo eletrônico; e promoção de oportunidades sociais que colaborem para a construção da cidadania plena.
\end{abstract}

Palavras-chave: Políticas de Informação; Governança Informacional; Governo Eletrônico; Letramento Informacional.

\begin{abstract}
This paper is a preliminary study focusing on specific policies, which investigates the electronic information available to citizens through government information policies in the State of Minas Gerais. According to Ferguson (2002, p.129), there is a strategy used by the British government which is guided by four principles: create services based on the choices of citizens, make government services more accessible, facilitate social inclusion and improve the use of information." These principles are used to guide this study, which aims to list the most accessed electronic services offered by the government of Minas Gerais, in response to the first principle. The study uses data submitted by the Central Superintendence of Electronic Governance. The MG Portal provides various services of interest to the society but which are unknown to the public. These services require an outreach work among citizens so they can use the e-gov sites made available by the government to minimize or solve the demand of society and try to reverse reputation for inefficiency of the public organization. In his study and work presented at the XI Enancib, Massensini (2010) points out the necessity to invest in telecentres as public access points; promote information literacy to educate the citizen to use digital and ICTs (Information and Communication Technologies) and participate of e-government; and provide social opportunities to collaborate for the construction of citizenship.
\end{abstract}

Keywords: Information Policy; Informational Governance; Electronic Government; Informational Literacy.

InCID: R. Ci. Inf. e Doc., Ribeirão Preto, v. 3, n. 1, p. 105-124, jan./jun. 2012. 


\section{Introdução}

Este trabalho é um estudo preliminar com foco em políticas públicas específicas, que possui como objeto a informação eletrônica disponibilizada ao cidadão, por meio de políticas de informação governamental, no Estado de Minas Gerais.

A disponibilização de informações governamentais por meio de sites, onde a sociedade seja capaz de utilizá-las para solucionar parte de suas demandas exige dos cidadãos um nível de conhecimento de uso das tecnologias da informação e da comunicação para que se tornem participativos no e-governo, porém cabe ao Estado diminuir a carência da população sobre o letramento informacional, conforme propõem Massensini (2010).

Deste modo, a prática da democracia digital torna-se importante quando relacionada à prática dos serviços de e-governo promovida pelo Estado, o que nos permite pensar nas políticas públicas capazes de promover a inclusão informacional do cidadão brasileiro e sua participação por meio da governança eletrônica.

São políticas públicas específicas: políticas de informação governamental. A informação governamental é reconhecida pelo Estado como imprescindível às políticas públicas.

Atualmente, órgãos e entidades públicas do Estado de Minas Gerais realizam ações para disponibilizar os serviços de e-governo com foco no cidadão, conforme o Projeto Estruturador Governo Eletrônico ${ }^{1}$. Ações de melhorias são necessárias para atingir a sociedade com a oferta de serviços eletrônicos, conforme a Superintendência Central de Governança Eletrônica do Estado de Minas Gerais ${ }^{2}$.

A Secretaria de Ciência e Tecnologia e Ensino Superior - SECTES, também, oferece programas: Centros Vocacionais Tecnológicos - CVT's, com a pretensão de promover a inclusão dos cidadãos nos espaços digitais em que se faz presente o Estado.

Desenhar e redesenhar os processos informacionais, disponibilizados à sociedade civil pela administração pública do Estado de Minas Gerais, pode ser uma forma de contribuir para a prática da inclusão informacional.

\footnotetext{
${ }^{1}$ MINAS GERAIS (Estado). Projeto estruturador do governo eletrônico. Disponível em: <http://www.egov.mg.gov.br/Projeto_estruturador_Governo_Eletronico-21>. Acesso em: 15 mar. 2011.

2 MINAS GERAIS (Estado). Prestação de serviços ao cidadão. Disponível em:

<http://www.egov.mg.gov.br/Prestacao_de_servicos_ao_cidadao-22> $>$. Acesso em: 15 mar. 2011.
} 
Assim, questiona-se: Quais serviços eletrônicos realizados pelo governo do Estado de Minas Gerais são mais acessados pelos cidadãos? Esses serviços eletrônicos foram criados de acordo com a necessidade requisitada pelo cidadão?

O que se percebe é a existência de um Estado Contemporâneo que se faz complexo em sua estrutura social e que exige o desenvolvimento de uma democracia capaz de responder às demandas por políticas públicas relacionadas à informação eletrônica.

Nos próximos tópicos apresentaremos alguns trabalhos que fundamentam o estudo, uma vez que se faz necessário desenvolver pesquisas, que discorram sobre governo eletrônico e políticas informacionais, em profundidade.

\section{Políticas de informação governamental e regime de informação}

A política de informação surge da necessidade de tratar melhor a prestação de serviços de informação pelo Estado ao cidadão. A avaliação da coleta de dados nos sites governamentais possibilita ao Estado analisar novas maneiras de melhorar os portais através da busca e do uso das informações acessados pelo cidadão, que procura utilizar alguns dos serviços disponíveis na Web.

Segundo González de Gómez (2002, p. 27), “o nexo da informação com a política seria então estabelecido por sua inclusão na esfera de intervenção do Estado, agora não só como dimensão de racionalidade administrativa, mas como fator estratégico do desenvolvimento científico-tecnológico”.

A necessidade que se faz presente na sociedade de um desenvolvimento científicotecnológico impulsiona as indústrias para a valoração da informação tanto como insumo quanto produto importante nos parques tecnológicos globais.

O capitalismo informacional, metamorfose do capitalismo antigo, responde à demanda por busca e uso da informação como moeda de negociação no novo mercado global, estimulado pelo desenvolvimento cientifico-tecnológico.

Assim, “[...] o Estado age como agente privilegiado de geração, recepção e agregação das informações [...]" (GONZÁLEZ DE GOMEZ, 2002, p. 27). 
Para González de Gomez, novos cenários políticos são construídos a partir da informação em rede:

[...] As novas tecnologias de comunicação e informação forneceria os meios para manter ativas as relações entre os agentes e as instituições envolvidos nas novas cadeias decisionais e acionais, com diversas modalidades de complexidade extensão: locais, regionais, transnacionais (CASTELLS, 1999; JESSOP, 1998 apud GONZÁLEZ DE GOMEZ, 2002, p.29).

As novas tecnologias fornecem, portanto, um suporte para o fortalecimento do "Estado em rede" - termo que se faz presente no Plano Mineiro de Desenvolvimento Integrado (PMDI) que busca desenvolver programas e políticas públicas, em que as secretarias de governo se relacionam no formato em rede, que "o Estado passa a atuar de forma transversal, estabelecendo laços com diferentes setores da sociedade, no sentido de responder as demandas, resolver problemas e propor estratégias customizadas de desenvolvimento" (MINAS GERAIS, 2011, p.42). A internet como espaço de universalização do acesso à informação torna-se local de "domínio político autônomo e capaz de organizar em uma sinergia própria todos os outros domínios organizacionais da comunicação e a informação [...]” (GONZÁLEZ DE GOMEZ, 2002, p. 31).

A "convergência digital" e a potencialidade para reunir fluxos de informação analógica e digital (BORGMANN, 200) são destacadas como o princípio operacional decisivo que desencadearia, com as redes eletrônicas, um processo irreversível de construção de um infrapoder informacional (GONZÁLEZ DE GOMEZ, 2002, p. 32).

Deste modo, a internet é percebida como espaço capaz de promover experiências democráticas e tendências monopólicas, mas que depende da utilização e do controle que se tem sobre as informações. Faz-se necessário pensar o papel do Estado nas formulações das políticas de informação, capaz de equilibrar o poder, em que se apresentam as economias globalizantes.

González de Gomez (2002, p. 34), buscando responder às mudanças para os novos cenários, opta por trabalhar com “o conceito de 'regime de informação', que designaria um modo de produção informacional dominante em uma formação social, conforme o qual serão definidos sujeitos, instituições, regras e autoridades informacionais [...].”

Assim, os serviços do Portal MG, serão analisados como regime de informação do Estado de Minas Gerais, de uma forma em que o cidadão possa interagir e participar das decisões políticas, como "cidadão empoderado", conforme González de Gomez (2002). 
Os estudos do uso da Internet pelos governos seguiriam três direções principais: no quadro das abordagens da "Nova administração pública", das teorias renovadas da "Governança" e associadas ao conceito de "citizens empowerment” (GONZÁLEZ DE GOMEZ, 2002, p. 35).

Para Marcondes e Jardim (2003, p. 1), “a informação governamental é um dos principais componentes dos dispositivos de mediação no jogo democrático que envolve Estado e Sociedade Civil", em que se faz importante o desenvolvimento das políticas de informação que fortaleçam a participação dos cidadãos nas decisões políticas.

Apresentar-se-á no próximo tópico alguns conceitos que possam contribuir para o desenvolvimento do termo governo eletrônico que "é muito abrangente e ainda carece de maior aprofundamento teórico e pesquisas no campo da Ciência da Informação", conforme Marcondes e Jardim (2003, p. 2).

\section{Governo eletrônico e governança informacional}

Em estudo publicado: Pesquisa sobre o Uso das Tecnologias da Informação e da Comunicação no Brasil - TIC governo eletrônico 2010³, o Centro de Estudos sobre o uso da Tecnologia da Informação e Comunicação - CETIC apresenta como seu objetivo produzir indicadores e estatísticas sobre o uso das tecnologias da informação e da comunicação no Brasil, provendo o Estado de informações necessárias ao planejamento dos serviços de egoverno.

Far-se-á, aqui, alguns apontamentos sobre o que a literatura apresenta como governo eletrônico, uma vez que o Estado Contemporâneo tem percebido na difusão das tecnologias da informação e da comunicação possibilidades de atendimento ao cidadão e de administrar os bens e serviços públicos.

O avanço da Tecnologia da Informação e da Comunicação (TIC) e, mais especificamente, da Internet, está sendo alardeado como uma oportunidade de transformar a relação entre governo e cidadão e entre serviços do governo e consumidores (FERGUSON, 2002, p. 103).

Deste modo, vários serviços públicos são disponibilizados via internet para uso do cidadão no dia a dia, uma vez que as novas tecnologias empregadas propiciam oportunidades de busca e uso dos serviços de informação.

\footnotetext{
${ }^{3}$ PESQUISA, 2010
}

InCID: R. Ci. Inf. e Doc., Ribeirão Preto, v. 3, n. 1, p. 105-124, jan./jun. 2012. 
Faz-se necessário apontar algumas definições sobre governança eletrônica, para compreender os serviços disponibilizados pelo governo eletrônico e acessados pelos cidadãos, conforme exposto no tópico: POLÍTICAS DE INFORMAÇÃO E SERVIÇOS ELETRÔNICOS.

Martin Ferguson (2002, p. 104) aponta a existência de várias definições e apresenta a do Gartner Group como sendo uma delas a que "trata tanto de governança como de serviços do governo".

O Gartner Group (2000) define governo eletrônico como sendo: a contínua otimização da prestação de serviços do governo, da participação dos cidadãos e da administração pública pela transformação das relações internas e externas através da tecnologia, da Internet e dos novos meios de comunicação (FERGUSON, 2002, p. 14).

Assim, a participação dos cidadãos na administração pública por meio das novas tecnologias é percebida como possibilidade de se aperfeiçoar os processos de negócio do governo com relação à prestação de serviços. Isto, por vezes, caminha em direção à democracia - participação do cidadão - digital.

Para Ferguson (2002, p.104), governança eletrônica é “a união dos cidadãos, pessoaschave e representantes legais para participarem junto ao governo das comunidades por meios eletrônicos".

Klaus Frey (2002, p. 148) aponta que "a world wide web não foi criada com a finalidade de promover cidadania democrática, mas possui, sem dúvida, grandes potencialidades democráticas, e pode ser usada para renovar modos de participação política e tomada de decisões".

No entanto, a participação política por meio das novas tecnologias exige a promoção da inclusão informacional do cidadão. Em contrapartida, saber buscar e fazer uso dessas informações e serviços eletrônicos exige do cidadão o letramento informacional para habilitálo a utilizar os serviços públicos eletrônicos.

O objetivo é transformar as condições para a participação do cidadão na governança de comunidades de três maneiras: permitindo a participação na Sociedade de Informação; criando infraestrutura para a Sociedade da Informação; promovendo um conceito de cidadania e de identidade cultural, usando as TICs (FERGUSON, 2002, p. 123).

Segundo Ferguson (2002, p.129), há uma estratégia, utilizada pelo governo britânico, norteada por quatro princípios: “a criação dos serviços com base nas opções dos cidadãos; 
tornar o governo e seus serviços mais acessíveis; inclusão social; melhoria na utilização da informação".

Deste modo, esses princípios nos servem aqui como norteadores, para este estudo que objetiva listar os serviços eletrônicos mais acessados do governo de Minas Gerais, exigindo posteriormente pesquisa de profundidade para analisar a acessibilidade desses serviços, pelos cidadãos; verificar o nível de inclusão social e apontar melhorias na utilização das informações disponíveis.

Para tanto, pretende-se utilizar dos dados a serem disponibilizados pela Superintendência Central de Governança Eletrônica, do Estado de Minas Gerais, para identificar os serviços mais utilizados, pelos cidadãos, no Portal MG.

Deste modo, busca-se fomentar, com algumas questões levantadas por Ferguson (2002, p.133-134), o debate sobre políticas de informação e governança eletrônica:

Como lidar com a exclusão digital? [...] como os governos irão manter-se em contato com o público em um mundo cada vez mais eletrônico? [...] como superar a mentalidade compartimentalizada das grandes organizações do governo? [...] como os governos financiarão o investimento 'inicial' necessário para a implementação de um governo eletrônico? [...] como integrar os blocos tecnológicos?

São questionamentos que servem como passos que precisam ser realizados em direção a Política e ao Estado Contemporâneo. No próximo tópico apresentaremos o entendimento de política e estado contemporâneo, para melhor desenvolvimento do estudo preliminar que aqui se faz.

\section{Política e estado contemporâneo}

A compreensão da expressão política pública exige-nos, antes, compreender o termo política que "[...] na linguagem comum ou na linguagem dos especialistas e profissionais, refere-se ao exercício de alguma forma de poder e, naturalmente, às múltiplas consequências desse exercício" (RIBEIRO, 1986, p. 13).

Tratar-se-á do poder simbólico mais a frente, por meio das ideias e pesquisas de Pierre Bourdieu, uma vez que "definir a Política apenas como algo relacionado ao poder não chega a ser satisfatório" (RIBEIRO, 1986, p. 14). 
O que se pretende mostrar com isso é que, queiramos ou não, estamos imersos num processo político que penetra todas as nossas atitudes, toda a nossa maneira de ser e agir, até mesmo porque a educação, tanto a doméstica quanto a pública, é também uma formação política (RIBEIRO, 1986, p. 22).

Assim, o que nos falta, por vezes, é a consciência do nosso papel político na sociedade e em todos os espaços sociais. "A Política, o jogo de poder - a 'transa' para se obter uma decisão qualquer - está em toda parte, na conduta humana", como indica João Ubaldo Ribeiro (1986, p. 24).

Há necessidade de se participar do Estado por meio das decisões que se materializam nas políticas públicas. O "Estado em ação" ou a "materialidade da intervenção do Estado" pode ser compreendido por meio das políticas públicas, conforme aponta Janete Azevedo (2004, p. 5).

Sendo assim, quando se enfoca as políticas públicas em um plano mais geral $\mathrm{e}$, portanto, mais abstrato isto significa ter presente as estruturas de poder $\mathrm{e}$ de dominação, os conflitos infiltrados por todo o tecido social e que têm no Estado o locus da sua condensação, como sugeriu POULANTZAS (1980). Em um plano mais concreto, o conceito de políticas públicas implica considerar os recursos de poder que operam na sua definição e que têm nas instituições do Estado, sobretudo na máquina governamental, o seu principal referente (AZEVEDO, 2004, p. 5).

A Política está diretamente relacionada à existência coletiva, impactando sobre o individual no espaço social - a sociedade; “[...] em toda sociedade há mecanismos estabelecidos, através dos quais as decisões públicas são formuladas e efetivadas" (RIBEIRO, 1986, p. 35).

Por outro lado, o interesse individual tornara-se mais visível após as transformações sociais, que provocaram divisões na estrutura da sociedade, gerando conflitos entre os atores políticos.

Assim, a solução dos conflitos sociais, por vezes, correspondem à vitória de uma das partes envolvidas. Os vitoriosos buscaram a institucionalização da dominação por meio do processo sucessório, para manterem-se no poder, surgindo as instituições que correspondem a símbolos e atitudes de poder. "A esse conjunto de instituições [...] dá-se o nome de Estado" (RIBEIRO, 1986, p. 43).

"Estado é a organização política e jurídica da sociedade, que muitas vezes, [...], chega a confundir-se com essa mesma sociedade" (RIBEIRO, 1986, p. 44). Sociedade esta que se 
estruturou nas transformações históricas que a humanidade registrou por meio de revoluções entre outros movimentos sociais.

Cabe ressaltar, relativo à institucionalização da dominação, que nos registros históricos da humanidade a força física, por muitos anos, fez dos mais fortes os líderes da comunidade. "Assim, a tecnologia, desde o começo, teve um papel muito importante. O controle da tecnologia passou a propiciar o exercício de um papel dominante nas decisões coletivas - a tecnologia se igualou ao poder. Quem tinha machado ou lanças tinha poder" (RIBEIRO, 1986, p. 37). Os avanços tecnológicos transformaram a sociedade, com consequências por todo o espaço social, impactando sobre o coletivo. Atualmente, o controle da tecnologia, inclusive de guerra, faz de alguns poucos Estados Nacionais líderes da "aldeia global".

Deste modo, o estudo realizado por Massensini (2010) serve para a compreensão de um período histórico - Moderno - responsável por parte da transformação pela qual passou o Estado, seguida pela reconfiguração da estrutura social. Este período pode ser entendido a partir do século XVII, com a Revolução Inglesa, prosseguindo com a Revolução Industrial e a Revolução Francesa, como a "Era das Revoluções". Período este seguido pela "Era dos Extremos", em que nações fazem uso das tecnologias de guerra para dominar a "aldeia global".

Para Bobbio (2000, p. 401), "pelos fins do século XIX e início do século XX, ocorreram transformações profundas na estrutura material do Estado de direito, havendo sido radicalmente alterada a forma da livre concorrência de mercado".

Compreende-se nesta análise de Norberto Bobbio que o Estado sofreu outra transformação que impactou sobre sua estrutura e sobre a vida dos cidadãos ao promover um novo Estado - Contemporâneo.

Uma definição de Estado contemporâneo envolve numerosos problemas, derivados principalmente da dificuldade de analisar exaustivamente as múltiplas relações que se criaram entre o Estado e o complexo social e de captar, depois, os seus efeitos sobre a racionalidade interna do sistema político. Uma abordagem que se revela particularmente útil na investigação referente aos problemas subjacentes ao desenvolvimento do Estado contemporâneo é a da análise da difícil coexistência das formas do Estado de direito com os conteúdos do Estado social (BOBBIO, 2000, p. 401).

Bobbio (2000) expõe nesta análise uma difícil coexistência entre os direitos que fundamentam as liberdades burguesas e a ação do Estado Social. Para ele os direitos sociais 
dizem respeito à participação no poder político, ou seja, um caminho pelo qual a "sociedade entra no Estado, modificando-lhe a estrutura formal".

O Estado Contemporâneo representa a força do mercado por meio do capital global que, no século XXI, se apresenta como capitalismo informacional, utilizando-se das tecnologias da informação e da comunicação que tanto impactam sobre a política econômica do Estado.

As revoluções discutidas no estudo de Massensini (2010), e que correspondem ao capitalismo metamorfoseado, são importantes para a compreensão do que se denomina de capitalismo informacional. Trata-se do capitalismo que se adapta às condições de mercado contemporâneo, atendendo às necessidades de consumo apoiadas nas informações disponibilizadas por meio das tecnologias da informação e da comunicação.

O que se pode visualizar por meio desta análise introdutória ao estudo é o fortalecimento das organizações nos diversos setores do capital econômico em detrimento do poder do Estado de direito.

Deste modo, as alternativas que se fizeram presentes aos debates na esfera pública neste início de século XXI ainda não responderam ao problema social do Estado Contemporâneo - a pobreza. O problema social, consequente das transformações pelas quais a sociedade passou com as revoluções, fez-se presente nas diversas classes sociais que seguiram o modelo de sistema econômico capitalista. E, outras propostas sociais também não foram capazes de responder a este problema, pois se fundamentavam no Mercado.

As relações de poder se fazem presentes nos vários espaços, sendo exemplificado pela economicização do Estado que não realiza mais tanta intervenção nas ações capitalistas da economia global, que define os caminhos que a sociedade precisa seguir para atingir o objetivo de ser desenvolvida - nos termos tecnológicos.

Os direitos sociais segurados na constituição são relativizados pelo capital global que, por vezes, minimiza a participação do cidadão nas ações políticas, e maximiza a participação deste em atuações econômicas que não conseguem responder às necessidades básicas para uma vida justa aos seus direitos.

Massensini (2010) apresenta uma relação entre a diminuição na participação política e o aumento na participação econômica do cidadão, quando levado em consideração a valoração do consumidor em detrimento do ator político.

InCID: R. Ci. Inf. e Doc., Ribeirão Preto, v. 3, n. 1, p. 105-124, jan./jun. 2012. 
A busca por respostas aos problemas sociais consequentes de um capitalismo informacional que se metamorfoseou durante o início do século XXI, suportado pelas novas tecnologias, sobrevivendo às crises mundiais, nos remete a pesquisas e questionamentos realizados por Eugênio Trivinho, Edilson Cazeloto, José de Souza Martins, Jessé Souza e Pierre Bourdieu.

Portanto, cabem análises das ações de governo, que são realizadas como políticas públicas, buscando responder à desigualdade social presente na sociedade brasileira. E, que impactam no desenvolvimento da cultura por meio das trocas simbólicas.

Para Bourdieu (1996), o espaço social no qual se está inserido é responsável por alimentar o desenvolvimento da sua cultura ao se submergir nesse lugar social em que se encontra. Assim, as condições históricas nas quais estão inseridos determinados grupos sociais correspondem à construção cultural criada e alimentada por eles dentro de determinados espaços sociais.

A cada classe de posições corresponde uma classe de habitus (ou de gostos) produzidos pelos condicionamentos sociais associados à condição correspondente e, pela intermediação desses habitus e de suas capacidades geradoras, um conjunto sistemático de bens e de propriedades, vinculadas entre si por uma afinidade de estilo (BOURDIEU, 1996, p. 21).

O habitus corresponde às características intrínsecas e relacionais de uma posição no espaço social, traduzindo os movimentos culturais e diferenciando determinados grupos sociais, que possuem sua própria linguagem e maneira de se comunicar por meio das diversas ferramentas.

Mas o essencial é que, ao serem percebidas por meio dessas categorias sociais de percepção, desses princípios de visão e de divisão, as diferenças nas práticas, nos bens possuídos, nas opiniões expressas tornam-se diferenças simbólicas e constituem uma verdadeira linguagem. [...] (BOURDIEU, 1996, p. 22).

Esta linguagem se traduz em aspectos da cultura, presentes nos diversos pontos da cultura digital, que promovem a construção de grupos sociais e de desenvolvimento de novas idéias.

O objetivo é compreender o papel do Estado, por meio de políticas públicas e serviços de e-governo, e as representações dos cidadãos como agentes presentes nos espaços digitais, como possibilidade de contribuir para o seu processo de inclusão informacional na esfera pública que se faz contraditória no espaço global. 
Deste modo, analisar o habitus que se constrói e distribui nas redes digitais do Estado, também, torna-se importante para a compreensão da cultura informacional que está disponível nas janelas digitais para o acesso da humanidade - os espaços públicos.

Para Bourdieu (1996, p. 49), devemos construir espaços sociais em que possam ser recortadas as classes. Assim, as classes se mostrariam diferenciadas dentro dos espaços sociais, onde cada qual possui as suas características culturais.

Assim, os espaços digitais tornam-se lugares importantes e interessantes para este estudo a partir da possibilidade de se visualizar quais características culturais estão sendo expressas e que refletem as ações dos atores sociais. Os serviços utilizados pelos cidadãos por meio dos sites do governo podem corresponder à demanda social.

Por outro lado, tanto o Estado quanto o Mercado são utilizados para responder a interesses específicos objetivados nas ações entre ambos, o que nos exige compreender quais serviços são mais acessados e a quem atendem nesses espaços, uma vez que esses são, por vezes, utilizados para construção e reprodução de uma cultura informacional que busca atender tanto à política de um quanto ao de outro.

A preocupação posta por Bourdieu (1996, p. 95) está no momento de se analisar o Estado, por meio de suas ações. Pois muitas análises se constroem no corpo próprio do Estado, reproduzindo desta forma uma das visões analisadas ao invés de realização de uma análise crítica.

Para Bourdieu (1996, p. 105), “o Estado contribui para a unificação do mercado cultural ao unificar todos os códigos - jurídico, linguístico, métrico - e ao realizar a homogeneização das formas de comunicação, especialmente a burocrática (por exemplo, os formulários, os impressos etc.)".

Deste modo, o Estado torna-se "[...] o lugar por excelência da concentração e do exercício do poder simbólico" (BOURDIEU, 1996, p.108).

Assim, o espaço social mostra-se lugar propício para as trocas simbólicas a que para Bourdieu (1996, p. 161): "trata-se de trocas que têm sempre verdades duplas, difíceis de manter unidas. [...]".

Esse trabalho de desvendamento, de desencantamento, de desmistificação não tem nada de desencantador: de fato, ele só pode se realizar em nome dos próprios valores que estão na base da eficácia crítica do desvendamento de 
uma realidade em contradição com as normas oficialmente professadas, igualdade, fraternidade e, sobretudo, no caso específico, sinceridade, desinteresse, altruísmo, em resumo, tudo o que define a virtude civil. [...] (BOURDIEU, 1996, p. 222).

Este é o cuidado de que devemos ter ao buscar nas janelas digitais a cultura informacional que nelas são construídas e distribuídas, pois se pode correr ao erro de promovê-la no momento de sua análise, reconstruindo e redistribuindo tal cultura.

Assim, "a cultura dominante contribui para a integração real da classe dominante (assegurando uma comunicação imediata entre todos os seus membros e distinguindo-os das outras classes); [...]", conforme Bourdieu (2010, p. 10), sugerindo-nos a legitimação de uma classe que exclui aqueles que não correspondem aos padrões culturais dominantes.

[...] É enquanto instrumentos estruturados e estruturantes de comunicação e de conhecimento que os sistemas simbólicos cumprem a sua função política de instrumentos de imposição ou de legitimação da dominação, que contribuem para assegurar a dominação de uma classe sobre outra (violência simbólica) dando o reforço da sua própria força às relações de força que as fundamentam e contribuindo assim, segundo a expressão de Weber, para a dominação dos dominados (BOURDIEU, 2010, p. 11).

Por outro lado, o que se percebe por meio do estudo realizado por Massensini (2010) são possibilidades de redução da desigualdade social, como sugerido a partir de “[...] pequenos espaços de cultura como o CVT Henfil, se adaptados às sugestões propostas nesta pesquisa, podendo servir para a formação de cidadãos que se construam conscientes e críticos".

No próximo tópico apresentaremos uma metodologia definida estudos de usuário, como forma de se compreender melhor os cidadãos usuários dos serviços disponibilizados pelo governo do Estado de Minas Gerais. 


\section{Os estudos de usuários e usabilidade}

Os estudos de usuários, como metodologia de análise daqueles que buscam e usam os serviços de informação, por vezes, disponibilizados nos diversos sites públicos, é uma maneira de se compreender os acessos realizados por esses visitantes que geram um tráfego na rede mundial de computadores, podendo desta forma aprimorar ou não as informações disponíveis no portal, que é o canal de comunicação da organização pública na internet.

Para Costa e Ramalho (2010, p. 9), “[...] um indivíduo pode estar incluso em várias categorias de usuários, desempenhando vários papéis nos momentos de sua vida, enquanto um ator social", o que nos exige analisá-lo presente em vários espaços digitais, podendo repetir seu acesso à mesma informação.

Deste modo, o mesmo usuário poderia acessar várias informações em várias páginas na internet, promovendo um volume de tráfego na rede. Aqui o foco estaria no usuário como visitante dos diversos sites.

Por outro lado, o foco nos sites exige-nos compreender tal visitante em seus diversos papéis enquanto um ator social único - visitante único, que realiza várias visitas em busca de informação para as suas demandas. Alguns usuários realizam buscas diretas, entrando o endereço do site desejado - tráfego direto, e outros utilizam das ferramentas de busca para encontrar as informações que procuram.

Assim, Costa e Ramalho (2010, p. 10) nos aponta duas abordagens:

1. Abordagem tradicional ou paradigma clássico - estudos direcionados sob a ótica do sistema de informação;

2. Abordagem alternativa ou paradigma moderno - estudos direcionados sob a ótica do usuário.

De forma que se pode, no presente artigo, considerar ambas as abordagens para entendimento tanto dos sistemas de informação organizacionais quanto o usuário. Apesar de que "[...] o paradigma moderno enfatiza o usuário, colocando-o numa posição ativa, fazendo com que as organizações e os sistemas de informação se adaptem às necessidades particulares dos usuários na tentativa de atendê-los" (COSTA; RAMALHO, 2010, p.11).

Ainda segundo Costa e Ramalho (2010, p. 22), os estudos de usuários somados ao estudo de usabilidade formam estudos híbridos de uso da informação, que pode contribuir 
consideravelmente para um aprimoramento da formatação dos serviços disponibilizados aos usuários dos serviços de informação.

Para Gasque e Costa, os estudos de usuários assumiram uma dimensão maior e mais complexa que, por vezes, estudos anteriores à década do ano 2000 nos apresentam.

[...] estudos de usuários de informação na ciência da informação como um todo, considerando os grupos pesquisados, passaram a abranger tanto o contexto organizacional quanto o comunitário e o de negócios, e não somente o contexto acadêmico ou industrial, como nos primeiros tempos (GASQUE; COSTA, 2010, p. 31).

Assim, o comportamento informacional tomou proporções mais complexas devido ao contexto informacional ao qual se inserem os usuários de informação, que, por vezes, buscam e usam das diversas possibilidades presentes na rede mundial de computadores. "Exige, ainda, o entendimento das relações estabelecidas em determinado espaço-tempo em que ocorrem ações de busca, uso e transferência de informação" (GASQUE; COSTA, 2010, p. 32).

Já no próximo tópico visualizaremos alguns serviços utilizados pelos cidadãos que se fazem presentes no espaço digital por meio dos serviços eletrônicos ofertados pelo governo do Estado de Minas Gerais. E, ainda, o nível de utilização desses serviços que exige análise quanto à presença de políticas informacionais no Estado mineiro. Afinal, a quantidade e a qualidade de serviços públicos disponíveis na internet reflete a inclusão do cidadão, conforme Marcondes e Jardim (2003, p. 6).

\section{Políticas de informação e serviços eletrônicos}

O CETIC (PESQUISA, 2010, p. 27), em estudo sobre o uso de TIC Governo Eletrônico no Brasil, publicou como sendo

[...] a principal forma de acesso aos serviços públicos a presencial, com preferência de atendimento presencial por $60 \%$ de indivíduos. No entanto, quando o cidadão utiliza a tecnologia como mediadora do acesso aos serviços públicos, $35 \%$ citaram a internet como principal forma de obtenção de algum serviço público, superando o telefone, com $8 \%$ dos entrevistados.

Atualmente o Governo do Estado de Minas Gerais disponibiliza aproximadamente 1.200 serviços em seu Portal MG <http://www.mg.gov.br>, onde há possibilidade do cidadão buscar e usar informações sobre diversos serviços de interesse. 
Entre os diversos serviços de interesse dos cidadãos foram listados os dez mais acessados, que correspondem à demanda sobre a busca e utilização do portal de informações governamentais de Minas Gerais. Mas, que não estão listados em ordem decrescente.

Emissão de atestado de antecedentes criminais;

Emissão da carteira de identidade - $1^{\mathrm{a}}$ via;

Emissão da carteira de identidade $-2^{\mathrm{a}}$ via;

IPVA - consulta de valores;

Alteração do titular da conta de energia elétrica;

Emissão da $2^{\mathrm{a}}$ via da conta de água;

Emissão da $2^{\mathrm{a}}$ via de conta de luz;

Consulta a situação do veículo;

Pagamento on-line da conta de água;

Solicitação de nova ligação de água; entre outros.

Estes serviços foram detectados através de uma ferramenta gratuita chamada Google Analytics $^{4}$ que é utilizada para medir o retorno e a viabilidade estratégia do site de internet avaliado mensalmente pela área de Governança Eletrônica do Estado de Minas Gerais para analisar os dados trafegados sobre o Portal MG, durante o período de 27/05/2011, 26/06/2011 com o intuito de aprimorar a disponibilidade e aplicabilidade dos serviços disponíveis aos cidadãos.

No período analisado o Portal MG recebeu 82.264 acessos (visitas) por meio de 323 origens e mídias eletrônicas de acesso à informação. O número absoluto de visitantes únicos, que são representados aos números de pessoas que acessam o site somente uma vez durante um tempo específico, corresponde a 65.064, ou seja, a diferença de 17.200 visitantes, do total de visitas, repetiu os acessos ao portal durante o período avaliado.

A média de páginas visitadas por dia é de 2,79 , por usuário, com um tempo médio de duração de aproximadamente $00 \mathrm{~h} 03 \mathrm{~min} 01 \mathrm{~s}$, com uma taxa de rejeição de $51.23 \%$ que corresponde a um percentual de visitas ao site por um tempo inferior a dez segundos.

Há variações de média de páginas visitadas quando analisado por dia da semana, o que se visualiza é que de segunda à quarta-feira existe um nível superior de acesso do que no fim de semana. São aproximadamente 10.000 acessos na segunda-feira enquanto no sábado estão

\footnotetext{
${ }^{4}$ Para maiores informações: Google analytics. Disponível em: <http://www.google.com/analytics〉. Acesso em: 16 jan. 2012.
}

InCID: R. Ci. Inf. e Doc., Ribeirão Preto, v. 3, n. 1, p. 105-124, jan./jun. 2012. 
próximos a 3.000 páginas visualizadas, ou seja, no primeiro dia da semana ocorre mais de 3 (três) vezes o número de acessos do que no final da semana.

Deste número de visitas realizadas houve 184.728 visualizações de páginas únicas de um total de 229.593 dos links de anexos de informacional do portal. Cabe ressaltar que das 82.264 visitas recebidas, $52.170(63,42 \%)$ são tráfego direto, que corresponde aos acessos das pessoas ao site através do navegador ao digitar o nome direto da URL (endereço da página) ou ao clicar nos favoritos que direciona ao link desejado, $23.278(28,30 \%)$ são mecanismos de pesquisa e $6.816(8,29 \%)$ são sites de referência.

Portanto, a porcentagem de acessos diretos ao Portal MG ultrapassa 60\%. Quando analisado o volume o que se pretende com a proposição de se utilizar dos Centros Vocacionais Tecnológicos é aumentá-lo, correspondendo a um número maior de visitas. E, quando analisado por palavras-chave o termo atestado de antecedentes criminais $m g$ aparece em primeiro lugar com 875 visitas, seguido por diário oficial mg com 681 visitas, entre outros mais, conforme relatório. Percebem-se, a partir da busca realizada por palavras-chave, alguns serviços ${ }^{5}$ requisitados pelos cidadãos.

A contagem de visitas do mesmo visitante, incluindo a atual, correspondente a uma vez é de 56.948 (69,23\%). A maioria dos usuários não repete suas visitas.

Deste modo, a proposição que aqui se faz é de se utilizar dos programas de inclusão desenvolvidos pelos projetos CVT's da SECTES para letrar os cidadãos na busca e uso de informações referentes aos serviços disponíveis no Portal MG. Assim, haveria divulgação do Portal MG e letramento dos cidadãos quanto ao uso dele.

A existência do módulo de internet durante os cursos articulados pelos programas de inclusão torna possível tal exercício junto aos alunos que estiverem cursando e praticando a busca e uso das informações disponíveis no Portal MG.

Sendo assim, a seguir ponderamos algumas considerações pertinentes ao processo político do governo eletrônico e de letramento informacional dos cidadãos para que se caminhe em direção de uma cidadania digital plena.

\footnotetext{
${ }^{5}$ Lista de palavras-chave do relatório do Google Analytics, utilizado para acompanhar o site.

InCID: R. Ci. Inf. e Doc., Ribeirão Preto, v. 3, n. 1, p. 105-124, jan./jun. 2012.
} 


\section{Considerações finais}

Inicialmente o que se mostrou neste estudo preliminar foram os serviços mais acessados pelos cidadãos por meio do Portal MG, cabendo na seqüência do estudo desenvolver uma pesquisa de profundidade para analisar a acessibilidade e verificar o nível de inclusão social, apontando melhorias.

O estudo demonstra que $63,42 \%$ das pessoas acessam o canal de comunicação do governo direto pelo nome do site, podendo ser devido aos trabalhos dos telecentros.

Outra questão, é que embora os serviços não sejam criados de acordo com a necessidade requisitada pelo cidadão eles podem ser remodelados conforme o acompanhamento e monitoramento de acesso. E, podem surgir novas solicitações de itens por parte dos usuários, que estão acessando o portal, para o gestor de informação.

Conclui-se que, o Portal MG têm atividades de monitoramento que são úteis para otimizar ou reorganizar, em seu site, os serviços de informação mais acessados pela população.

Deste modo, a "materialidade da intervenção do estado" por meio das políticas públicas específicas relativas às políticas de informação exige-nos pesquisas de profundidade com um grau de detalhamento maior e um desenvolvimento das discussões sobre os termos que se relacionam: políticas de informação e governança eletrônica.

O Estado Contemporâneo apresenta-nos uma relação complexa que impacta sobre o corpo político desse Estado que se aperfeiçoa em redes que atingem todos os espaços: político, econômico, social e tecnológico em que estão presentes os cidadãos. Neste Estado Contemporâneo as políticas de informação sofrem mutações com a intervenção do mercado, sobre as decisões políticas, reduzindo os direitos sociais e de consumo.

Há necessidade de avaliar as políticas de informação e as práticas de governança eletrônica como resposta à demanda por políticas públicas. No Estado de Minas Gerais, o Portal MG oferece vários serviços que são de interesse da sociedade, cabendo maior divulgação desses entre os cidadãos para que eles possam utilizar-se dos serviços de governo disponíveis nos sites das entidades públicas para minimizar ou solucionar suas demandas. E, ainda, ao utilizar dos serviços avaliá-los como possibilidade de aperfeiçoamento. 
Em sua dissertação e trabalho apresentado no Enancib XI, Massensini (2010) apontou a necessidade de se investir em telecentros, como pontos de acesso público; em letramento informacional, como ensino da linguagem digital que capacita o cidadão para o uso das TICs e participação no governo eletrônico; e promoção de oportunidades sociais que colaborem para a construção da cidadania plena.

\section{Referências}

AZEVEDO, J. M L. A educação como política pública. 3. ed. Campinas: Autores Associados, 2004. BOBBIO, N. Dicionário de política. Brasília, UNB, 2000.

BOURDIEU, P. O poder simbólico. 13. ed. Rio de Janeiro: Bertrand Brasil, 2010. Razões práticas: sobre a teoria da ação. Campinas: Papirus, 1996.

COSTA, L. F.; RAMALHO, F. A. A usabilidade nos estudos de uso da informação: em cena usuários e sistemas interativos de informação. Perspect. ciênc. inf., Belo Horizonte, v. 15, n. 1, abr. 2010. Disponível em:

<http://www.scielo.br/scielo.php?script=sci_arttext\&pid=S141399362010000100006\&lng=pt\&nrm=iso>. Acesso em: 14 maio 2012.

FERGUSON, M. Estratégias de governo eletrônico: o cenário internacional em desenvolvimento. In: EISENBERG, J.; CEPIK, M. Internet e política: teoria e prática da democracia eletrônica. Belo Horizonte: Ed. UFMG, 2002.

FREY, K. Governança eletrônica: experiências de cidades europeias e algumas lições para países em desenvolvimento. In: EISENBERG, J.; CEPIK, M. Internet e política: teoria e prática da democracia eletrônica. Belo Horizonte: Ed. UFMG, 2002.

GASQUE, K. C. G. D.; COSTA, S. M. S. Evolução teórico-metodológica dos estudos de comportamento informacional de usuários. Ci. Inf., Brasília, v. 39, n. 1, abr. 2010. Disponível em <http://www.scielo.br/scielo.php?script=sci_arttext\&pid=S010019652010000100002\&lng=pt\&nrm=iso >. Acesso em: 14 maio 2012.

GONZALEZ DE GOMEZ, M. N. Novos cenários políticos para a informação. Ci. Inf., Brasília, v. 31, n. 1, jan. 2002. Disponível em: <http://www.scielo.br/scielo.php?script=sci_arttext\&pid=S010019652002000100004\&lng=pt\&nrm=iso>. Acesso em: 15 ago. 2011.

MARCONDES, Carlos Henrique, JARDIM, José Maria. Políticas de informação governamental: a construção de governo eletrônico na administração federal do Brasil. DataGramaZero: revista de ciência da informação, v. 4, n. 2, abr. 2003. 
Ciência da Informação) - Escola de Ciência da Informação, Universidade Federal de Minas Gerais, Belo Horizonte, 2010.

MINAS GERAIS (Estado). Secretaria de Estado de Planejamento e Gestão. Plano mineiro de desenvolvimento integrado. Minas Gerais, 2011. Disponível em:

<http://www.seplag.mg.gov.br/governo/publicacoes/plano_mineiro_des_integrado.asp $>$. Acesso em: 13 maio 2012.

PESQUISA sobre o uso da tecnologia da informação e comunicação no Brasil: TIC governo eletrônico 2010. São Paulo: Núcleo de Informação e Coordenação do Ponto BR, 2010. 100 p. Disponível em: <http://op.ceptro.br/cgi-bin/indicadores-cgibr-ticegov2010? pais $=$ brasil\&estado $=m g \&$ setor - publico $=$ setor-publico\&age $=$ de $-35-\mathrm{a}-44-$ anos\&education=pos-mestrado\&purpose=politicas-publicas $>$. Acesso em: 20 mar. 2010.

RIBEIRO, J. U. Política. 9. ed. Rio de Janeiro: Nova Fronteira, 1986. 